\title{
Entrepreneurial ecosystems in cities: establishing the framework conditions
}

Article

Accepted Version

Audretsch, D. B. and Belitski, M. (2017) Entrepreneurial ecosystems in cities: establishing the framework conditions. Journal of Technology Transfer, 42 (5). pp. 1030-1051. ISSN 1573-7047 doi: https://doi.org/10.1007/s10961-016-9473-8 Available at https://centaur.reading.ac.uk/61156/

It is advisable to refer to the publisher's version if you intend to cite from the work. See Guidance on citing.

To link to this article DOI: http://dx.doi.org/10.1007/s10961-016-9473-8

Publisher: Springer

All outputs in CentAUR are protected by Intellectual Property Rights law, including copyright law. Copyright and IPR is retained by the creators or other copyright holders. Terms and conditions for use of this material are defined in the End User Agreement.

\section{www.reading.ac.uk/centaur}

\section{CentAUR}

Central Archive at the University of Reading

Reading's research outputs online 


\title{
Entrepreneurial Ecosystems in Cities - Establishing the Framework Conditions
}

\author{
David B. Audretsch, Maksim Belitski
}

\begin{abstract}
This study focuses on regional entrepreneurial ecosystems and offers a complex model of start-ups, Regional Entrepreneurship and Development Index (REDI) and six domains of the entrepreneurial ecosystem (culture, formal institutions, infrastructure and amenities, IT, Melting Pot and demand). Altogether they capture the contextual features of socioeconomic, institutional and information environment in cities. To explain variations in entrepreneurship in a cross-section of 70 European cities, we utilize exploratory factor analysis and structural equation modelling for regional systems of entrepreneurship using individual perception surveys by Eurostat and the REDI Index. This study supports policymakers and scholars in development of new policies conducive to regional systems of innovation and entrepreneurship and serves as a basis for future research on urban entrepreneurial ecosystems.
\end{abstract}

Keywords: start-ups, entrepreneurial ecosystem, Europe, city, REDI

JEL-code: L26, O31, R11

Audretsch, David B., School of Public and Environmental Analysis, Indiana University, Bloomington, 1315 E. Tenth St., Bloomington, IN 47405 e-mail: daudrets@indiana.edu

${ }^{1}$ Maksim Belitski, Henley Business School, University of Reading, Whiteknights, Reading, RG6 6UR, United Kingdom. email: m.belitski@ reading.ac.uk

\section{ACKNOWLEDGEMENT}

We are grateful to the participants of the Conference on National Systems of Entrepreneurship in Mannheim 20-21 November 2014, Babson Conference in Natick, MA on June 10-13, 2015 and second International workshop in on Entrepreneurial Ecosystems, Innovation and Regional Competitiveness at Henley Business School, University of Reading, Dec 12-13, 2014 for their helpful comments. We appreciate suggestions from Professors Erik Stam, Mark Casson, Tomacz Mickiewicz and Dr. Julia Korosteleva. Special thanks to Prof. Erik E. Lehmann, Prof. Georg Licht and other Special Issue editors for enriching the contributions of this work.

\section{INTRODUCTION}

\footnotetext{
${ }^{1}$ Corresponding author
} 
A holistic approach to entrepreneurship and innovation has become the most recent trend in the entrepreneurship and innovation policy (Autio et al. 2014). Almost two decades studies have focused on national settings that influence innovation (Nelson 1993; Edquist 1997), rather than regional innovation systems (Cooke 2001). Independently to the level of settings, systems of innovation represent a combination of socioeconomic, political, institutional and organisational factors that influence innovation activity and business growth (North 1990; Edquist 1997). Later, Edquist (2005) posits, that innovation system consists of two main elements: institutions and companies.

Although, the most recent trend in the national systems of innovation policy is an increasing emphasis on taking a more multi-functional and multi-disciplinary approach (Edquist 2005; Acs et al. 2014), including the evolution of a florid technology transfer literature, with insights from entrepreneurship, economics and management (Audretsch et al. 2015a), the literature of innovations systems adds little to a holistic approach to entrepreneurship (Stam 2014; Szerb et al. 2013; Mason and Brown 2012; Audretsch and Link, 2015). In fact, studies on innovation systems have been missing focus on individual characteristics, personalities and individual's behavior which play an important role in the innovation process and add to a better understanding the entrepreneurial activity (Qian et al 2013).

A holistic approach to entrepreneurship has become a new step in the European entrepreneurship policy (Stam and Nooteboom 2011; WEF 2013; Acs et al. 2014; Autio et al. 2014; Levie and Autio 2014; Ghio et al. 2014; Audretsch and Lehmann 2016), focusing on the role of the entrepreneurial ecosystem and the processes of how it is developed, adapted and sustained. Holistic approach advocates researching entrepreneurial activity as an individual behavior of entrepreneurs embedded within a local content (Szerb et al. 2013) rather than focusing on entrepreneurial activity in isolation (Wright and Stigliani 2012). Within this framework, the systems approach to innovation is extended to address new firm formation as an important reflection of entrepreneurial and innovation

Activity, as opposed to focus on incumbent firms (Qian et al. 2013). Entrepreneurship needs to be closely linked with the regional innovation systems, which includes regions, innovation, network, learning and interaction (Cooke 2001).

The key insight being that entrepreneurial activity needs to be studied at a local context, where the decisions are taken place, individual traits matter most and the research is scarce (Acs and Szerb 2010; Szerb et al. 2013). The systemic (holistic) approach to regional systems of entrepreneurship may differ depending on the type of a system. It can be industry specific (e.g. IT cluster in Reading, UK, mobile cluster in Helsinki, Finland) or may include several industries (e.g. Silicon Valley, London Roundabout). Therefore we define systems of entrepreneurship (further ecosystem) as institutional and organisational as well as other systemic factors that interact and influence identification and commercialisation of entrepreneurial opportunities. Systems of entrepreneurship are geographically bounded e.g. Austin, Texas, Cambridge and Oxford in England, Boston area in Massachusetts, Aalto in Finland serve as an example of cities with thriving entrepreneurial ecosystems. Indeed regulation, institutions and norms, infrastructure, city amenities, access to finance and demand vary largely between regions and cities where new ideas and knowledge reside (Bosma and Sternberg 2014; Glaeser et al. 2014; Stuetzer et al. 2014; Belitski and Desai, 2015). Entrepreneurial ecosystem framework determines who becomes an entrepreneur, how individual's perception support entrepreneurial decision-making in the area, and how various domain effect entrepreneurial action and outcomes of the ecosystem (Andersson and Koster 2011; Autio et al. 2014). A significant progress in the holistic approach to regional systems of entrepreneurship has been the development of the Regional Entrepreneurship and Development Index - REDI (Szerb et al. 2013). 
Building on regional entrepreneurship Qian et al. (2013), Szerb et al. (2013), Audretsch and Lehmann (2016) and systems of innovation literature (Nelson 1993; Edquist 1997, 2005) it reveals a widespread acceptance that new business creation exhibit systemic properties when studied at a various spatial scale (Cooke 2001; Acs et al. 2014). First, empirical data shows significant differences between European regions across countries and within the same country in terms of start-ups and business growth (Bosma, Schutjens and Stam 2009; Belitski and Korosteleva 2010; Fritsch and Storey 2014; Audretsch et al. 2015b). This is consistent with the notion that entrepreneurial performance is driven by complex, systemic interactions (Audretsch, Keilbach and Lehmann 2006; Levie and Autio 2008, 2011). Second, socioeconomic, institutional, political, organisational and increasingly important informational and technology context differences are persistent over time across regions and countries (Edquist 1997; Autio et al. 2014), suggesting that entrepreneurial performance is driven by path-dependent processes (Levie and Autio 2011; Fritsch and Wyrwich 2014). Third, the major function of systems of entrepreneurship is to pursue entrepreneurial activity which spills over through discovering and exploiting of entrepreneurial opportunities (Audretsch and Lehmann, 2005; Acs et al. 2013b) as well as creation of institutions and the building of capacity that will sustain regional economic development (Feldman 2014).

This study aims to develop a model capturing both regional and local systemic factors to better understand and explain variations in entrepreneurial activity. There are three important contributions for scholars and policy we do.

Firstly, methodologically it is important to develop metrics in order to determine the strengths and weaknesses of a regional system of entrepreneurship and the relationship between each domain of the system, so that most relevant components can be assessed and targeted (Mason and Brown 2012). Second, we estimate the model controlling for joint effect of the REDI Index on start-ups (Szerb et al. 2013; Levie and Autio 2014) and contrast this effect to the six-domain latent construct. This framework describes socio-economic, informational and institutional aspects of entrepreneurship ecosystem. This provides initial clues on how entrepreneurial ecosystem framework conditions affect the rate of entrepreneurial activity. Third, building on the regional systems of innovation and entrepreneurship literature (Nelson 1993; Edquist 1997, 2005; Isenberg 2010; Feld 2012; Szerb et al. 2013) we append the ecosystem model with the informational domain e.g. access to information and Internet. In doing do we attempt to define the role of ICT as an important factor which supports entrepreneurial ecosystem framework (Zacharakis et al. 2003; Liu et al. 2015) by increasing the speed of knowledge spillover (Acs et al. 2009). Fourth, the model can be applied as a platform that facilitates the development of new policies and correction the existing entrepreneurship and urban policies to support entrepreneurial discovery (Szerb et al. 2013; Qian et al. 2013) in various European and the US regions.

The results enable policy-makers and scholars to identify and improve the systemic and framework conditions of entrepreneurship ecosystem and to better explain variations in entrepreneurship across regions.

\section{THEORETICAL BACKGROUND}

\subsection{Entrepreneurial ecosystems}

Entrepreneurship plays an important role in economic development (Audretsch and Lehmann 2005; Audretsch et al. 2006; Acs et al. 2008), but its decision-making does not happen in isolation from a local context where entrepreneurs operate (Acs et. al. 2014). In other words, it is recognized that both individual entrepreneurial action and contextual factors (Acs et al. 2014) are important (Mason and Brown 2012). Creating a local context conducive to 
entrepreneurship and economic development requires the myriad public and private decisions that determine the character of place (Feldman 2014). Firstly, the individual action is a result of attitudes, aspirations and opportunities given in a certain context where individuals work and live (Wright and Stigliani 2012; Wright 2014; Szerb et al. 2013). Secondly, the local context influences the type of start-ups: necessity driven vs. opportunity driven (Stam 2014) and how fast they grow (Mason and Brown 2012).

Although the local context research and systemic approach to understanding entrepreneurship has been limited (Acs et al. 2014; Autio et al. 2014), the research in regional entrepreneurship is well established (Marshall 1920; Saxenian 1994; Audretsch et al. 2006; Stam 2008, 2014; Bosma et al. 2012). In particular the research on positive and negative externalities that impact regional and urban entrepreneurial activity in regions (Sternberg 2009; Estrin et al. 2013; Stenholm et al. 2013; Fritsch and Storey 2014) knowledge spillover theory of entrepreneurship (Audretsch and Lehnman 2005; Audretsch and Belitski 2013, 2015; Ghio et al. 2014; Belitski and Desai, 2015) and entrepreneurship as an urban event (Bosma, Schutjens and Stam 2009; Fritsch and Wyrwich 2014). A constructive multi-level approach to study entrepreneurial activity has been offered by the Global Entrepreneurship Monitor (GEM) team (Reynolds et al. 2005; Levie and Autio 2008; Bosma et al. 2008, 2009; Acs et al. 2008; Stuetzer et al. 2014) who investigated attitudes, ability, and aspirations and integrates these with system-level factors that regulate entrepreneurship processes in a certain country region. This approach follows the recent literature on cluster emergence and evolution (Braunerhjelm and Feldman 2008) where the role of an individual is to exploit competitive advantages, generate resources and create new businesses is in the centre of a system (Saxenian 1994; Acs et al. 2013a, 2014).

Policy makers and scholars are now recognising the relevance of a more systemic support towards more holistic approach on developing entrepreneurial culture, greater access to information, networks and entrepreneurial finance, information access and infrastructure (Zacharakis et al. 2003; Isenberg 2010; Rodriguez-Pose 2013; Audretsch et al. 2015c). During the recent years, both theoretical and empirical research on entrepreneurial ecosystems has been growing (Napier and Hansen 2011; Malecki 2011; Feld 2012; Wright 2014). Acs et al. (2014) defined entrepreneurial ecosystems as "a dynamic, institutionally embedded interaction between entrepreneurial attitudes, ability, and aspirations, by individuals, which drives the allocation of resources through the creation and operation of new ventures". In their definition authors meant community entrepreneurial ecosystems that are likely defined by physical territorial boundaries. Stam (2014) provided another insight on entrepreneurial ecosystem as "an interdependent set of actors that is governed in such a way that it enables entrepreneurial action”. In addition to Feld (2012) and Stam (2014), Mason and Brown (2012) put high growth businesses with significant management functions and undertaking R\&D at the heart of an entrepreneurial ecosystem (Bosma and Stam 2012).

In this study we understand entrepreneurial ecosystem as a dynamic community of interdependent actors (entrepreneurs, supplies, buyer, government, etc.) and system-level institutional, informational and socioeconomic contexts (Levie and Autio 2014; Wright 2014). Agents interact via information technologies and networks to create new ideas and more efficient policies (Zacharakis et al. 2003; Deloitte 2012). These policies are explained largely in one word 'jobs' (Coad et al. 2014). Our definition draws attention to the important interaction between contextual domain of the ecosystem on the one hand, and individual decision-making driven by attitudes and perception of the context, at the other. To pursue opportunities an entrepreneur needs access to all framework conditions of the ecosystem that are conducive to business with a minimum number of the bottlenecks (Levie and Autio 2014).

Examples of well-known entrepreneurship ecosystems in regions and cities may include more 
traditional such as Silicon Valley, Route 158, Boston and Stanford cluster in the US with its world-class educational institutions and spin-offs, (Szerb et al. 2013), and more recent such as Aalto area near Helsinki, Finland, London Roundabout and the Thames Valley Business hub in Berkshire, England.

\subsection{Drivers of Entrepreneurial ecosystems and hypothesis formulation}

The existence of entrepreneurial opportunities cannot be established ex ante, but often implicitly assumed drawing upon the individual's perceptions of the feasibility of the desired action and entrepreneurial cognition (Wright and Stigliani 2012; Acs et al. 2013b). To conclusively validate and access an opportunity, both perceptions by an entrepreneur and the local context are important. Individual views and personal judgement about the access to labour market and finance, demand, infrastructure and cultural norms, administrative support and efficiency, competitive advantage (Saxenian 1994; Wright 2014) form a framework condition of the ecosystem enabling to challenge the status quo. This aspect reinforces the exploratory nature of entrepreneurial ecosystems- as individuals envisage the potential while they perceive strengths in a given region or city (Bosma and Stam 2012). How far geographically will an entrepreneur judge? Given the conceptualisation and physical boundaries of the entrepreneurial ecosystem, scholars advocate the local level appears to be an appropriate aggregate level to many entrepreneurial decision-making and resource accumulation by entrepreneurs (Stam 2014; Stam and Nooteboom 2011; Sternberg 2009; Stuetzer et al. 2014). In particular, entrepreneurship at a city-level provides a relevant socioeconomic and institutional context of within the entrepreneurial ecosystem. In this study we focus on the entrepreneurial ecosystem framework conditions including the importance of IT alignment, which helps individual decision-making, judgement and the ability to foresee opportunities. While creating an efficient entrepreneurial ecosystem, it is important to adjust good regional practices with integrating historically evolved local conditions (Isenberg 2010; WEF 2013). Our approach follows Isenberg (2010), Stem (2014), Szerb et al. (2013), Levie and Autio (2014) but extends their works in three important ways: first, we describe the relationships within all six domains of the ecosystem framework conditions and drop the least relevant. Second, we add access to information factor within the framework conditions emphasizing an importance of information technology for entrepreneurial action (Zacharakis et al. 2003; LEAD 2014). Third, we explain a joint relationship between REDI Index, the ecosystem framework conditions and the start-up rate advocating for the REDI as a powerful instrument to predict entrepreneurial activity in cities, additional to regions. REDI Index has become very popular and efficient in explaining entrepreneurship activity in regions, identifying the bottlenecks and policy implications (Szerb et al. 2013; Levie and Autio 2014).

\section{Culture and norms}

Culture and norms constitute one of four framework basic conditions of the entrepreneurial ecosystem (Stam 2014). Norms are much more specific than the context conditions within the entrepreneurial ecosystem approaches as they are seen as a specification of the formal institutions and culture (Szerb et al. 2013).

Norms and trust that reward entrepreneurial action will provide additional resources and enhance cooperation between the actors (Acs et al. 2014; Estrin et al. 2013). The norms and culture appeals to collective (DiMaggio and Powell 1983) and relates to a perception of trust and safety within neighbourhood, including the entrepreneurial communities. Enabling a combination of trust between the community members, neighbourhood and city safety is an important domain of a vibrant entrepreneurial ecosystem (Beinhocker 2007).

West European communities have traditionally been perceived as facilitators of entrepreneurial behaviour with safer and more trusted neighbourhoods, whilst Eastern 
European societies with higher bureaucracy and corruption have been perceived as lacking trust (Aidis, Estrin and Mickiewicz 2008, 2012). Individual entrepreneurs may choose not to start a business in corrupted, unsafe areas where customers do not trust their suppliers and vice versa (Aidis et al. 2008). We hypothesise:

Hypothesis 1: Local culture that facilitates trust and safety is likely to improve the entrepreneurial ecosystem.

\section{Physical infrastructure and amenities}

Cities will thrive and grow if they provide amenities and infrastructure that are attractive to its high human capital residents (Glaser et al. 2001). Physical conditions such as infrastructure and amenities (green spaces, theatres, museums, cinemas, coffee shops and art galleries), transport links either foster or constrain interaction between the agents of the entrepreneurial ecosystem. Infrastructure enhances connectivity and linkages that facilitate the recognition of opportunities (Audretsch et al. 2015c). Former highlight that it is physical infrastructure that facilitates connectivity between people is most conducive to entrepreneurship as it enables labour mobility, enhances exchange of knowledge and information. In doing so it further increases returns to investment in a region. Along with cultural amenities, transport and infrastructure facilitate the establishment of new networks, easing business communications, brining high-quality labour and new high-tech industries in cities (Belitski and Desai 2015). Good working conditions certainly affect the vibrancy of the local ecosystem and the quality of capacity in a local community, which enables entrepreneurs to develop a geographic community of common interest around their new ideas and technology (Feldman 2014). Developed physical infrastructure and capacity building bring pro-active people together, but also local and regional authorities, researchers and scholars, education institutes, non-for-profits, public leaders, societal organisations, creating so-called third spaces in the ecosystem (Stam 2014). Limited evidence on the relationship between physical infrastructure and entrepreneurship exist with Woolley (2014) found an important role of creation and configuration of the contextual infrastructure for nascent technology entrepreneurship in new industries (e.g. nanotechnology). An increasing demand for business incubators, accelerators and newly established gazellerators exist where amenities and links are available and efficient. As the value of time is being uplifted individuals will be avoiding areas where the transport is unreliable and connection insecure (Glaeser et al. 2001). Long-time commuting and poor connections within the city will distort the communing patterns and increase the cost for producers, suppliers and customers.

Whilst a substantial research on the role of physical infrastructure and amenities has been done (Saxenian 1994; Audretsch et al. 2015c), it lacks insight into the individual perceptions and how it reflects entrepreneurial ecosystem show how the elements of infrastructure configure and interact with the other elements through systemic coevolution (Woolley 2014). Increases in the consumption amenities and better physical conditions including infrastructure and connectivity (Glaeser et al. 2014) will raise population, employment, mobility and other intermediate services, creating new market niches for new ideas (Audretsch and Belitski 2013, 2015; Belitski and Desai, 2015).

Hypothesis 2: Transport connections and city amenities are likely to improve entrepreneurial ecosystem.

\section{Formal institutions}

Engaging the private sector and reforming bureaucratic and regulatory framework is in a heart of an efficient entrepreneurial ecosystem (Aidis et al. 2008; Isenberg 2010; Audretsch 
and Lehmann 2016). Entrepreneurs are discouraged from starting up a new business if they are constrained by bureaucracy, numerous local regulations and procedures and time requirements (McMullen, Bagby and Palich 2008) as well as the large government size (Aidis et al. 2012). Efficient administrative services, prioritization in allocation of resources and government support in providing jobs and finance (North 1990; Estrin et al. 2013; Stenholm et al. 2013) creates conducive ecosystem to start-up business and change individuals' perceptions on resource allocation, administration support and trust. This relates to the demand-side public interventions, to identify better allocation criteria to public funds with the aim to support start-ups and regional development (Audretsch et al. 2015a). Efficient government increases demand and supply for private and public services which may result in higher growth rate in the entire economy. The positive outcomes of efficient administrative services and resource allocation will create stability and make place more attractive to live, work and invest. The recent literature on the role and the size government in the local and national economy in regards to entrepreneurship, describes the role of regulation and government efficiency to start-ups and growth (Aidis et al. 2008, 2012; Bruton, Ahlstrom and Li 2010). Efficient government is positively associated with ecosystem which is conducive to entrepreneurial entry (Baumol, Litan and Schramm 2009; Korosteleva and Belitski 2015). This is also consistent with the notion of the 'rules of game' and 'players' addressed by North (1990).

Hypothesis 3: Responsibly spent resources and efficient administration services are likely to improve the entrepreneurship ecosystem.

\section{Information technologies and Internet}

Digital age is characterised by rapid technological change putting firm's capability to manage and manipulate information at the heart of firm's ability to survive and prosper (Cohen and Schmidt 2013). Key technologies available via internet able to change the basic tenant of competition are cloud computing, social media, internet of things, mobile computing and big data analytic (LEAD 2014). Such technological delivered and connected via internet enable better understanding, processing, adoption and application of new technologies. Access to information and enabled by internet speeds up and improves the way the information flows and how new innovative products and services are conceived, developed, produced and accessed (Yoo et al. 2010).

With a business environment currently being transformed by digital technologies and Internet, fast and reliable access is needed for disrupting existing businesses and opening new opportunities for business and leadership (Liu et al. 2015) An entrepreneurial ecosystem with embedded advance technologies and higher Internet connectivity at home and in the neighbourhood could be the ideal catalyst to make the most of the huge potential of digital technologies in Europe (Deloitte 2012) which facilitates start-ups and high growth.

Apart from making full use of existing technologies available via Internet, the innovative use of internet and orchestration of existing technologies is a powerful way for start-ups to improve business competence. Although the perceptions of individuals in regards to these new technologies and their use are hard to estimate, the availability of Internet as facilitator and a gateway to technologies is feasible to estimate.

Hypothesis 4: Internet access and connectivity is likely to improve the entrepreneurial ecosystem.

\section{Melting Pot Index}

Technology, talent and tolerance - the " $3 \mathrm{~T}$ " concept described by Florida's "The rise of 
creative classes" (2004) has been recognized as an important pillar of innovation, growth and entrepreneurship (Florida et al. 2008; Audretsch and Belitski 2013, 2015; Belitski and Desai 2015). Florida (2004) suggested the Melting Pot Index as a proxy for diversity, tolerance and integration. Individual's perceptions of foreigners being well integrated in a city facilitate the Florida's 3T. In particular, tolerance to diverse ideas and way of thinking, race and culture creates a special ecosystem where a pull of cultures becomes a norm. It also adds to city's amenities that stimulate a fly of talent in a city (Florida 2004; Glaeser et al. 2010). Diverse cities provide a platform for greater networking and communications between agents of various background and experiences, facilitating information and experience exchange. This may generate new ideas and speed up knowledge and information diffusion. Diversity and integration as an indicator of the Melting Pot aligns with a concept of 'Cool Cities' which have drawn policy-makers and scholars attention within the US and Europe as clusters for new ideas and businesses growth (Florida 2004; Nathan 2012).

Hypothesis 5: Foreigners being well-integrated are likely to improve the entrepreneurial ecosystem.

\section{Demand and workforce}

The regional demand and supply is often linked to population growth and density (Reynolds et al. 1994). The authors pointed out population growth and density undoubtedly affect the number of entrepreneurs. Further research has also demonstrated that entrepreneurs favour larger market potential and agglomeration economies (Glaeser et al. 2014) which enable higher externalities and spillovers (Audretsch et al. 2006; Ghio et al. 2014), large economies of scale and gives further incentives to innovate and grow (Audretsch 2007; Szerb et al. 2013; Feldman 2014).

While market size is important (Delmar and Davidsson 2000) for economic growth and employment, high demand for labour and high wages may discourage individuals to starting their own business due higher opportunity costs. It will drug labour force away from start-ups and small businesses, which pay lower wages and are associated with a high risk. Large market may not offset these high opportunity costs (Audretsch et al. 2006).

This may be a problem for early-stage growth and start-ups in particular. Demand for labour increases pressure on a real estate market with higher rents and prices for housing in places of desired residence. High rent and real estate prices on the one hand are an indicator of growth and regional economic development. On the other hand, lower availability of housing will discourage people from moving into a city as it slices their life quality. The impact of high demand for workforce and housing will therefore have an ambiguous impact on the rate and quality of entrepreneurial activity.

Hypothesis 6: The impact of high demand for labour force and housing on entrepreneurial ecosystem is ambiguous.

\section{METHODOLOGY}

\subsection{Data}

Our main data source is the Eurostat Statistical Database (Eurostat 2014). We utilize perception survey data on 70 European cities and the Urban Audit data during 2004- 2010 period. Perception surveys took place in random telephone interviews, 500 citizens in each city were asked about their perception of various aspects of the quality of life in "their" city 
related to the framework and systemic conditions of the entrepreneurial ecosystem (Stam 2014). These perception surveys allow for comparisons between perceptions and "real" data from various statistical sources on issues such as urban security, culture and norms, labour market conditions, use of IT, labour and house demand, physical infrastructure and life quality. The first perception survey was made in 2004 in 31 cities in the EU-15, with a smaller sample per city the latest survey was made in 2009 with 75 cities. When cleaned for missing data for the framework conditions we were left with 70 cities. Table 1 summarizes the list of cities in this study. Table 2 illustrates summary statistics of six main domains of the entrepreneurial ecosystem framework. It was built using factor analysis described in the next section. The source data is divided into three periods during 2004-2010.

Although the number of observation for each city varies between 2 or 3 (Table 1) it is enough to estimate the model (Szerb et al. 2013). Framework conditions of the entrepreneurial ecosystem (e.g., six domains specified in table 2) tend to be path dependent and selfreinforcing in regions and cities (Levie and Autio, 2011; Fritsch and Wyrwich 2014) and it is rare for this set-up to change during a short time period.

\section{"Insert Table 1 Here"}

"Insert Table 2 Here"

\subsection{Measures}

\subsubsection{Dependent variable}

Individual entrepreneurs find it easy to innovate in ways that challenge the established status quo unlike the established businesses (Zahra and Wright 2011). The challenge in the established status quo is operationalised through creating a new business (Audretsch 2007; Acs et al. 2008; Acs et al. 2013a, 2013b). Our depended variable is a proportion of start-ups in a city (Acs et al. 2009; Bosma and Sternberg 2014). The local nature of start-ups is best evidenced by the fact that most firms are started in or very near to the place of residence or work (Stam 2014).

\subsubsection{Explanatory variables}

Countries, but also regions and cities create a framework conditions that is conducive to entrepreneurship, mentioned as an "entrepreneurial climate" (Andersson and Koster 2011) or an entrepreneurial ecosystem (Stam 2014; Levie and Autio 2014). This explains differences in entrepreneurship across various spatial units, but also explains why regional patterns in entrepreneurship are persistent over time (Levie and Autio, 2011)

We follow Acs et al. (2013, 2014), Stam (2014) and Szerb et al. (2013) and operationalise six main domains or framework conditions of an entrepreneurial ecosystem. These are culture and norms, infrastructure and amenities, formal institutions, internet access and connectivity, the Melting pot index and demand.

To measure all six domains of the framework conditions we use Eurostat Urban perception surveys with individuals responding to various questions related to institutional and socioeconomic content of a city where they live. More details measurement of our framework conditions (see Table 2). All perceptions indicators utilise continuous 0 to 100 scale, where zero is inefficient and 100 is exceptionally efficient help (Noorderhaven, Thurik, Wennekers, and van Stel 2004; McMullen, Bagby and Palich 2008).

We perform exploratory factor analysis with the individual perception variables to determine factors related to different characteristics of local content. Our pattern matrix offers a clearer picture of the relevance of each variable in the factor loadings. These are the weights and 
correlations between each variable and the factor. The higher the load the more relevant in defining the factor's dimensionality. Based on this criteria and a 0.6 threshold Table 4 six factors were identified (Table 3). The rotation oblique promax which produces orthogonal factors. This means that factors are not correlated to each other. This setting is recommended when a scholar want to identify variables to create indexes or new context variables without inter-correlated components. For a robustness check we have tried various option of factor rotation. The following loading (domains) of the framework conditions were identified: loading on Factorl constitute 'culture' context, items loading on Factor 2 constitute 'infrastructure' context, items loading on Factor 3 constitute 'formal institutions' context, items loading on Factor 4 constitute 'internet and IT context', item loading on Factor 5 make up the Melting Pot context and finally loading on factor 6 - "demand" context. All value are positive which mean that the relationship is direct except of Factor 5 with the GDP associated negatively with the factor loading and negatively with the higher level of the Melting Pot.

The last column of rotated factor loadings (pattern matrix) is unique variance of each variable. Except of a variable 'transport' with $20 \%$ unique varience, the rest of variables on the contrary have low variance not accounted by other variables, for example safety score 2 has only 5\% varience not chared with other variables. Table 3 lists the two Cronbach alpha and inter-item correlation coefficients. Both for inter-item correlation and a Cronbach alpha we applied 0.7 threshold of statistical significance of a factor. As presented in Table 3, in each of the six retained factors measures load on different factors; and therefore indicates and justifies the content validity of identifying six distinctive conditions of entrepreneurial ecosystem model. We retain and save six factors to create a latent variable and describe the framework conditions in structural equation modelling.

\section{"Insert Table 3 Here"}

\subsubsection{Control variables.}

Our main control variable is the REDI Index. REDI addresses the interaction between individuals and their contexts that ultimately determines the magnitude of economic and societal benefits delivered through entrepreneurship (Szerb et al. 2013; Levie and Autio 2014). The REDI is a complex index of regional entrepreneurship that incorporates both individual and regional levels of analysis. The REDI itself is a project supported by the European Commission (Acs et al. 2014) which has become an extension of GEDI project (Acs and Szerb 2010; Acs et al. 2013a). Jointly controlling for the framework conditions and the REDI in our structural model enables better prediction. It adds to the power of association between the framework conditions of entrepreneurial ecosystem and the start-up rate solving the omitted variable bias (Stam 2014). Including both framework conditions (Mason and Brown 2012) and the REDI (Szerb et al. 2013; Levie and Autio 2014) in a horse-race will demonstrate the power of the bottleneck leveraging method and the individual's perceptions method in capturing the local context of the ecosystem.

\section{ANALYSIS}

The first step of our analysis is exploratory factor analysis. From the Rotated factor loading (pattern matrix) we retained six factors associated with six domains of the entrepreneurial ecosystem framework. Additional to the previously studied culture, formal institutions, demand, physical infrastructure and amenities (Stam 2014; Mason and Brown 2012) we included two important domains of the entrepreneurial ecosystem framework: the Melting Pot Index (Florida et. al., 2008) and the internet access and connectivity (Deloitte 2012). We further develop the structural equation model (SEM) which includes retained factor loadings, 
rather than separate variables (McCann and Ortega-Argilés 2013). All six domains constitute to a latent variable - framework conditions (see Figure 1).

The choice of SEM is determined by associations within the various institutional and socioeconomic contexts of entrepreneurial ecosystem, the relationship which is complex and inter-related (e.g. Isenberg 2010; Acs et al. 2013a, 2014; Stam 2014). SEM is a popular technique of choice for economic and management scholars (Hancock and Mueller 2006; Hooper, Coughlan and Mullen 2008). We used maximum likelihood estimation with missing values and performed a series of robustness checks to cut-offs for various indices, filter the conflicting results and analyse the goodness of fit. For example, we applied robust and clustered robust standard errors by city controlling for a spatial inter-dependence, we experimented with missing and non-missing values, survey estimation. We conducted a test of goodness of fits comparing baseline vs. saturated in a chi-square test, root mean squared error of approximation, various information indices, indices for comparison against baseline and measures based on residuals. We calculated the post-estimation criteria and accessed them following (McDonald and Ho 2002) and found most superior fit.

Measures included in our SEM in Figure 1 provide the most fundamental indication of how well the proposed entrepreneurship theory fits the data. Figure 1 presents the results of SEM with factors as variables used to build the latent variable and the REDI Index.

\section{"Insert Figure 1 here"}

In a nutshell, we started with six factors to calculate the latent variable of the framework conditions. Chi-Square statistic was rejected at 1 percent significance level due to small sample size. Our small sample of 950 observations including missing values and the ChiSquare statistical power may not discriminate between good fitting models and poor fitting models (Kenny and McCoach 2003). Due to the restrictiveness of the Chi-Square we calculated alternative indices to assess model fit.

Second, our RMSEA is 0.09 which is statistically significant but critical with the recommendations for a cut-off point reduced considerably and is now in the range of 0.05 to 0.07. After the correction of the model this value went down to 0.07 which is considered an indication of fair fit and values above 0.09 indicated weak fit (Hancock and Mueller 2006).

Third, the GFI increases as the number of parameters increases with traditionally cut-off point of 0.90 has been recommended for the GFI (Hancock and Mueller 2006). Our GFI was 0.75 which is greater than 0.7 , however after improvement and correction of the model it appeared as 0.92.Related to the GFI is the AGFI which adjusts the GFI based upon degrees of freedom, with more saturated models reducing fit. Our information criteria AIC and BIC have gone down to high 10770.896 and 10882.594 accordingly after adjustment to the model. Fourth, given the complexity of SEM, it is not uncommon to find a weak fit. Allowing modification of the model with dropping factor 5 referred to "Melting Pot" and factor 6 as "Demand" improved results and the goodness of fit. We also introduced the covariance between the residuals of factor 1 "Trust" and factor 3 "Formal institutions". We grounded this into a theory of governance as more efficient allocation of resources by the local government and efficiency of administration improve the level of trust in the community (Aidis et al. 2008, 2012; Estrin et al. 2013). Residuals are unobserved factors that may affect both formal institutions and trust e.g. corruption level which is not in the model.

Fifth, each construct should be modelled in conjunction with every other construct in the model to determine whether discriminant validity has been achieved. After dropping factor 5 and factor 6 we allowed only four domains in the framework conditions. This correction improved considerably the fit. 
Sixth, we further moved to hypotheses testing. Hypotheses one to four were supported; while hypotheses five and six were not supported. We hypothesized that efficient administrative services and allocation of resources, both referred to formal institutions will be associated positively with entrepreneurial ecosystem (hypothesis 3 ). This hypothesis is supported at $1 \%$ significance level. Hypothesis one states that residents' perception of safe and clean neighbourhoods, where people can be trusted altogether referred to cultural and normative context are positively associated with ecosystem and it was supported. Hypothesis two is supported as well and this is the strongest significance. It provides evidence that physical infrastructure and city amenities are most important in creating conducive conditions for business. Finally, access to internet is crucial in IT and business alignment and creating an ecosystem of entrepreneurship (Liu and Li 2015). In particular access to technologies via Internet is important in selling and winning new customers. Access to information through Internet enables a broader spectrum of business activities and opportunities to be found in the market as an interaction between the agents (e.g. blogs, feedback, social media, etc.).

One of the main findings of this study is in measuring the impact of entrepreneurial ecosystem on entrepreneurial activity. In testing the model we also compared and contrasted the joint impact of the REDI Index and the entrepreneurial ecosystem framework conditions in their ability to predict the level of entrepreneurship. The REDI and the framework conditions latent variables in our model were applied jointly to correct for possible omitted variable bias.

As illustrated in Figure 1 and Table 4 both the REDI and framework conditions construct are positively associated with entrepreneurial start-ups supporting the nexus: Framework conditions- the REDI- start-up rate. The impact of a latent variable is higher than the REDI and both are statistically significant. There could be two explanations. First, higher impact of the framework is due to complex and compound indictor of the framework conditions of entrepreneurial ecosystem. It includes 4 aggregated domains each of those described by various aspects of socioeconomic, institutional and informational context of a city. Second, the framework conditions are calculated using the perception surveys at a city level. This is the same level as our dependent variable, while the REDI was resigned to predict the quality of entrepreneurial ecosystem in regions. Our four domains of framework conditions add to explanatory power of the REDI at a city-level. Not surprisingly, error terms within the "trust" and "formal institution" domains of the framework are positively correlated with the covariance between two residuals being statistically significant at 1 percent significance level (Table 4).

\section{"Insert Table 4 Here"}

\section{RESEARCH IMPLICATIONS}

Research on entrepreneurial ecosystem is fairly young (Mason and Brown 2012; Acs et al. 2014; Autio et al. 2014). The proposed framework conditions (Isenberg 2010; WEF 2013; Stam 2014) form a basis for future theoretical and empirical research on entrepreneurial ecosystems, but it lacks one important domain - internet access and connectivity. This may be crucial for start-ups as IT and business alignment has become one of the main strategic advantages of business (Liu and Li 2015). Although start-ups and SMEs consider access to internet as a strategic weapon and a survival tool (LEAD 2014) scholars have not yet introduced this dimension into entrepreneurship ecosystem studies. Therefore inclusion of informational context is necessary and can contribute to a better understanding of the entrepreneurial ecosystem. In addition, the framework conditions lack more holistic and 
multi-level approach, e.g. inclusion of both city and regional controls of the entrepreneurial climate while predicting the start-up rate (Bosma and Sternberg 2014).

This study defined efficient entrepreneurial ecosystem as a complex system of interactions between agents within various socioeconomic, institutional and informational contexts which generate more new businesses and growth. We answer three main questions: (1) which contexts constitute an entrepreneurial ecosystem (Stam 2014)? (2) what is the role of individual perceptions in regard to formal institutions, norms and culture, infrastructure, amenities and IT in individuals decision-making to start a new firm? (3) do regional context (the REDI) and the local context (framework conditions) play an important role in facilitating start-up rate? Four out of six domains within the entrepreneurial ecosystem framework were found important to enhance entrepreneurial activity in European cities: culture and norms, infrastructure and amenities, formal institutions, internet access and connectivity. The REDI calculated using GEM data (Reynolds et al. 2005; Bosma et al. 2008, 2009; Szerb et al., 2013) and the framework conditions based on perception surveys by Eurostat (2014) predict the level of entrepreneurial activity in cities.

We propose the following policy action: (1) enable greater labour mobility in allocation of resources and reforming formal institutions to improve the reliance on administrative support, including financing entrepreneurship and resource allocation to help start-ups (e.g. Horizon 2020, Lisbon agenda, Cohesion policy, national entrepreneurship support schemes) (Levie and Autio 2014; Horizon 2020). Although excessive administrative support is not supportive to entrepreneurship, efficient administration enhances entrepreneurial start-ups and promotes growth (Aidis et al. 2012); (2) combining public and entrepreneurship leaders is important for private-public partnership which should add a stimulus to less motivated public sector. In addition the role of entrepreneurial leaders and e-leaders need to be uplifted. These are leaders who combine various domains of the ecosystem together within the IT alignment to be supported (Zacharakis et al. 2003). Information technologies and Internet need closer alignment with entrepreneurial ecosystem aiming for high growth (Bosma and Stam 2012; Stam 2014; Liu and Li 2015); (3) improving cultural facilities (e.g. coffee shops, bars, theatres, museums, green areas, libraries, parks, clubs and other cultural places) will add to city's attractiveness of cities as ecosystems (Florida et al. 2008). Cultural amenities are cityspecific and cannot be moved, but created which is known to attract creative class and highly skilled human capital (Glaeser et al. 2001; Florida 2004); (4) growing entrepreneurship culture and exercising a feeling of embeddedness (e.g. Your Reading, Love your city) that is one of the core determinants of individual choice to start a business in a local area. In particular these actions include incentivising educational programs and projects targeting communities; (5) stimulating entrepreneurial awareness and their access to growth finance which will select individuals with higher human capital into entrepreneurship (Stam 2008). A particular focus should go to high-growth businesses, tailoring the demand side public interventions to identify better criteria to reach the second stage growth projects quickly (Audretsch et al. 2015a).

Another important research implication is a joint test for the REDI and the framework conditions (Szerb et al. 2013; Stam 2014; Levie and Autio 2014). The model justified the use of REDI as a powerful instrument in explaining the failure and success of the system at both regional and city levels. This finding in regard to inclusion of REDI is important to tailor national and regional policies and in allocation of resources across regions (e.g. EU Structural and Cohesion funds). Policies in European cities need to focus on entrepreneurial policy design based on distinctive regional competitive advantages and the bottlenecks (Acs et al. 2014). Identifying these strengths and weaknesses in regards to entrepreneurial activity in regions and cities will be a priority for local policy-makers towards creating Smart 
Specialization Strategies and implementing the global 'Horizon 2020' strategy for cities (Horizon 2020).

The REDI Index and four established framework conditions of the entrepreneurial ecosystem taken together provide a robust guidance for the search of prospective strengths and weaknesses in entrepreneurship support policies. From a public policy perspective, it is important to recognise the role of the framework conditions to address entrepreneurship policy that are likely to lead to lower start-up rates.

\section{LIMITATIONS AND FUTURE RESEARCH}

This empirical analysis is based on the assumption that perception about various socioeconomic, informational and institutional contexts in a city where respondents live has a strong impact on an individual decision to start a business. Of course a limitation of this study is the framework conditions of the entrepreneurial ecosystem are limited to four domains. The true relationship is far more complex (Mason and Brown 2012; Autio et al. 2014). Future research on capturing interactions between the agents (Stam 2014), accounting for both private and public decision-making mechanisms is needed (Feldman 2014). This will allow creating a multilevel, multi-component interactive model where framework and systemic conditions along will create individual choices of starting a business. Consequently, optimising and changing the dimensions of a particular city does not mean optimising the whole regional entrepreneurial ecosystem. We also assume that all dimensions require approximately the same effort to improve by the same magnitude, all normalised and measured on a scale 0 to 100 in the perception survey (Eurostat 2014), however this may not be the case. Although all variables are compatible across 0-100 scale, the weighting mechanism has not been applied by region, for example, as it is complex to assign priorities to people's perception between different places and different conditions of the ecosystem, that vary in their geolocation, history, culture and sectoral structure.

The future research will deal with the multi-level factor models of interactions between actors and supply of necessary resources (e.g. labour, capital, FDI, outsourcing), cultural interaction and exchange (migration, Melting Pot cities, cultural events and labour pull), infrastructure support (e.g. multimodality access to cities, developing infrastructure). Scholars need to demonstrate how entrepreneurial ecosystems enable or constrain such multi-level interrelations at the local and other levels (e.g. industry-city-country; individual-regionnational, etc.).

\section{CONCLUSIONS}

The aim of this study was to investigate variation in entrepreneurial activity in cities.

Building on Isenberg (2010), Malecki (2011), Feld (2012), Qian et al. (2013), Acs et al. (2013, 2014) Szerb et al. (2013) we contribute to the literature on innovation systems by implementing a holistic approach to regional system of entrepreneurship. We explicitly assumed that an individual is at the heart of an ecosystem using individuals' perceptions about the local context influence decision-making and entrepreneurial activity. We also join Autio et al (2013) and Napier and Hansen (2011) in their focus on individual's embeddedness within local framework conditions. The study implements a holistic approach to entrepreneurship with the research objective to model regional and urban systems of entrepreneurship taking into account regional framework conditions (REDI) and all important factors that influence entrepreneurial ecosystem. A two-step structural model is proposed based on the literature that examines the 
relationship between entrepreneurship, culture, institutions, infrastructure, information, diversity and demand (Edquist 1997; 2005), highlighting the role of geography, knowledge and ICT (Cooke 2001; Deloitte 2012; Ghio et al. 2014)

We contribute to the literature by: (1) demonstration the impact of both regional context proxied by the REDI Index and the local context proxied by the framework conditions of the ecosystem on start-ups rate in cities. Both REDI and the framework conditions are complementarity and enable better understanding an 'entrepreneurship ecosystem' function; (2) measurement and justification of holistic approach through inclusion of all four domains of the entrepreneurship system framework conditions. In particular, we extended the previous models of regional entrepreneurship systems (Mason and Brown, 2012; Qian et al. 2013; Stam, 2014) with so far ignored domain - access to Internet and connectivity; (3) development of urban entrepreneurial ecosystem model which can be applied as a platform that facilitates the development of new policies exploiting both the REDI at a regional level and framework conditions of entrepreneurial ecosystem at a local level (Szerb et al. 2013).

Another key finding of this study lies in the strong association between ICT and entrepreneurship (LEAD 2014; Liu and Li 2015). Exploitation of new technologies and business and IT alignment is important for both general entrepreneurship and high technology entrepreneurship. Public policies allowing faster access to information and Internet may further lead to a more entrepreneurial activity and more innovation. Finally, we emphasise the importance of complementarity between framework and systemic conditions of regional systems of entrepreneurship for higher efficiency.

\section{REFERENCES}

Acs, Z. J., Desai, S., \& Klapper, L.F. (2008). What does “entrepreneurship" data really show? Small Business Economics, 31(3), 265-281.

Acs, Z.J., Braunerhjelm, P., Audretsch, D.B., \& Carlsson, B. (2009). The knowledge spillover theory of entrepreneurship. Small Business Economics, 32(1), 15-30.

Acs, Z. J., \& Szerb, L. (2010) The Global Entrepreneurship and Development Index 2011. Cheltenham: Edward Elgar Publishers.

Acs, Z. J., Szerb, L., \& Autio, E. (2013a). The Global Entrepreneurship and Development Index 2013. Edward Elgar Publishers, Cheltenham.

Acs, Z. J., Audretsch, D. B., \& Lehmann, E. E. (2013b). The knowledge spillover theory of entrepreneurship. Small Business Economics, 41(4), 757-774.

Acs, Z. J., Autio, E., \& Szerb, L. (2014). National Systems of Entrepreneurship: Measurement Issues and Policy Implications. Research Policy 43(3), 476-449.

Aidis, R., Estrin, S., \& Mickiewicz, T. (2008). Institutions and entrepreneurship development in Russia: a comparative perspective. Journal of Business Venturing 23, 656-672.

Aidis, R., Estrin, S., \& Mickiewicz, T. (2012). Size matters: entrepreneurial entry and government. Small Business Economics 39, 119-139.

Andersson, M., \& Koster, S. (2011). Sources of persistence in regional start-up ratesevidence from Sweden. Journal of Economic Geography 11(1), 179-201.

Audretsch, D. B., \& Lehmann, E.E. (2005). Does the knowledge spillover theory of entrepreneurship hold for regions? Research Policy, 34(8), 1191-1202.

Audretsch, D.B., Keilbach, M.C., \& Lehmann, E.E. (2006). Entrepreneurship and Economic Growth. Oxford University Press, USA

Audretsch, D.B. (2007). The Entrepreneurial Society. Oxford University Press, Oxford.

Audretsch, D. B., \& Belitski, M. (2013). The missing pillar: The creativity theory of knowledge spillover entrepreneurship. Small Business Economics, 1-18, doi 10.1007/s11187- 


\section{3-9508-6}

Audretsch, D. B., Lehmann, E. E., Paleari, S., \& Vismara, S. (2015a). Entrepreneurial finance and technology transfer. The Journal of Technology Transfer, 1-9, doi: 10.1007/s10961-0149381-8

Audretsch, D. B., Belitski, M., \& Desai, S. (2015b). Entrepreneurship and economic development in cities. The Annals of Regional Science, 1-28.

Audretsch, D. B., Heger, D., \& Veith, T. (2015c). Infrastructure and entrepreneurship. Small Business Economics, 44(2), 219-230.

Audretsch, D. B., \& Belitski, M. (2015) Creativity Spillover of Entrepreneurship Theory: Evidence from European Cities. In C. Karlsson, U. Gråsjö and S. Wixe. (Eds.), Innovation and Entrepreneurship in the Global Economy: Knowledge, Technology and Internationalization. London: Edward Elgar.

Audretsch, D.B., \& Link, A.N. (2015). Valuing an Entrepreneurial Enterprise, in: D.B. Audretsch, C. Hayter and A.N. Link (eds), Concise Guide to Entrepreneurship, Technology and Innovation, Chelterham: UK: Edward Elgar.

Audretsch, D.B., \& Lehmann, E.E. (2016). The Seven Secrets of Germany. Oxford University Press.

Autio, E., Kenney, M., Mustar, P., Siegel, D., \& Wright, M. (2014). Entrepreneurial innovation: The importance of context. Research Policy, 43(7), 1097-1108.

Baumol, W.J., Litan, R.E., \& Schramm, C.J. (2009). Good capitalism, bad capitalism, and the economics of growth and prosperity. New Haven, CT: Yale University Press.

Belitski, M., \& Korosteleva, J.A. (2010). Entrepreneurial activity across European cities (Interactive paper). Frontiers of Entrepreneurship Research, 30(4), 12.

Belitski, M., \& Desai, S. (2015). What drives ICT clustering in European cities?. The Journal of Technology Transfer, 1-21, doi: 10.1007/s10961-015-9422-y

Belitski, M., \& Desai, S. (2015). Creativity, entrepreneurship and economic development: city-level evidence on creativity spillover of entrepreneurship. The Journal of Technology Transfer, 1-23.

Li, K., Godley, A., Belitski, M., Li, W., Manwani, S. (2015). The importance of e-leadership in meeting digital challenges. Computerweekly.com. Retrieved March 1, 2016 at: http://www.computerweekly.com/opinion/

Beinhocker, E. (2007). The Origin of Wealth: The Radical Remaking of Economics and What it Means for Business and Society. London: Random House Business Books.

Bosma, N., van Stel, A., \& Suddle, K. (2008). The geography of new firm formation: Evidence from independent start-ups and new subsidiaries in the Netherlands. International Entrepreneurship and Management Journal, 4(2), 129-146.

Bosma, N., Acs, Z.J., Autio, E., Coduras, A., \& Levie, J. (2009). Global entrepreneurship monitor: 2008 executive report. Babson Park, MA: Global Entrepreneurship Research Consortium.

Bosma, N., Hessels, J., Schutjens, V., Van Praag, M., \& Verheul, I. (2012). Entrepreneurship and role models. Journal of Economic Psychology, 33(2), 410-424.

Bosma, N., Schutjens, V., \& Stam, E. (2009). Entrepreneurship in European Regions: Implications for Public Policy, in: J. Leitao en R. Baptista (eds), Public Policies for Fostering Entrepreneurship: A European Perspective, New York: Springer: 59-89.

Bosma, N.S., \& Stam, E. (2012). Local Policies for High-Employment Growth Enterprises. Report prepared for the OECD/DBA International Workshop on "High-growth firms: local policies and local determinants".

Bosma, N.S., \& Sternberg, R. (2014). Entrepreneurship as an urban event? Empirical evidence from European cities. Regional Studies, 48(6), 1016-1033.

Braunerhjelm, P., \& Feldman, M. (2008). Cluster genesis: technology-based industrial 
development. Economic Geography, 84(2), 245-246.

Bruton, G.D., Ahlstrom, D., \& Li, H.-L. (2010). Institutional theory and entrepreneurship: where are we now and where do we need to move in the future? Entrepreneurship Theory and Practice, 34(3), 421-440.

Coad, A. Daunfeldt, S-O. Johansson, D., \& Wennberg, K. (2014). Whom do high-growth firms hire? Industrial and Corporate Change, 23, 293-327.

Cohen, J., \& Schmidt, E. (2013). The new digital age: Reshaping the future of people, nations and business. Hachette UK.

Cooke, P. (2001). Regional innovation systems, clusters, and the knowledge economy.

Industrial and Corporate Change, 10, 945-974.

Deloitte (2012) DG Enterprise-Doing business in the digital age: the impact of new ICT developments in the global business landscape Market analysis \& foresight scenarios report. Retrieved October 15, 2014 at: http://www.iabeurope.eu/files/5313/6852/1955/2012-12 06_eu20study_market_analysis_and_foresight_scenarios_report_final_3.pdf

Delmar, F., \& Davidsson, P. (2000). Where do they come from? Prevalence and characteristics of nascent entrepreneurs. Entrepreneurship \& regional development, 12(1), 123.

DiMaggio, P.J., \& Powell, W.W. (1991). Introduction. In W.W. Powell and P.J. DiMaggio (Eds.), The new institutionalism in organizational analysis (pp. 1-38). Chicago: University of Chicago Press.

Edquist, C. (1997). Systems of Innovation: Technologies, Institutions and Organizations.

London: Pinter.

Edquist, C. (2005). Systems of Innovation. In J. Fagerberg, D.C. Mowery and R.R. Nelson

(Eds.), The Oxford Handbook of Innovation. New York: Oxford University Press.

Estrin, S., Korosteleva, J., \& Mickiewicz, T. (2013) Which institutions encourage entrepreneurial growth aspirations? Journal of Business Venturing, 28(4), 564-580

Eurostat. (2014). Perception surveys and Urban audit. Retrieved on October 15, 2014 at:

http://epp.eurostat.ec.europa.eu/portal/page/portal/region_cities/city_urban/perception_survey

Feld, B. (2012). Startup Communities: Building an Entrepreneurial Ecosystem in Your City.

New York: Wiley.

Feldman, M. P. (2014). The character of innovative places: entrepreneurial strategy, economic development, and prosperity. Small Business Economics, 43(1), 9-20.

Florida, R.L. (2004). The Rise of the Creative Class. New York: Basic Books.

Florida, R.L., Mellander, C., \& Stolarick, K. (2008). Inside the black box of regional development: Human capital, the creative class and tolerance. Journal of Economic Geography, 8, 615-649.

Fritsch, M., \& Storey, D. (2014). Entrepreneurship in a Regional Context - Historical Roots and Recent Developments. Regional Studies, 48, 939-954.

Fritsch, M., \& Wyrwich, M. (2014) The Long Persistence of Regional Levels of Entrepreneurship: Germany 1925 to 2005. Regional Studies, 48, 955-973

Ghio, N., Guerini, M., Lehmann, E. E., \& Rossi-Lamastra, C. (2014). The emergence of the knowledge spillover theory of entrepreneurship. Small Business Economics, 1-18, doi: $10.1007 / \mathrm{s} 11187-014-9588-\mathrm{y}$

Glaeser, E.L., Kolko, J., \& Saiz, A. (2001). Consumer city. Journal of economic geography, $1(1), 27-50$.

Glaeser, E.L., Rosenthal, S.S., \& Strange, W.C. (2010). Urban economics and entrepreneurship. Journal of Urban Economics, 67(1), 1-14.

Glaeser, E.L., Ponzetto, G.A., \& Tobio, K. (2014). Cities, skills and regional change. Regional Studies, 48(1), 7-43. 
Hancock, G.R., \& Mueller, R. O. (2006). Structural Equation Modeling: A Second Course. Charlotte. NC: Information Age Publishing.

Hooper, D., Coughlan, J., \& Mullen, M.R. (2008). Structural Equation Modelling: Guidelines for Determining Model Fit. The Electronic Journal of Business Research Methods, 6(1), 53 60.

Horizon (2020). European Commission. Retrieved on June 30, 2014 at: http://ec.europa.eu/programmes/horizon2020/

Qian, H., Acs, Z.L., \& Stough, R. (2013). Regional systems of entrepreneurship: the nexus of human capital, knowledge and new firm formation. Journal of Economic Geography 13, 559-587.

LEAD (2014). E-Leadership Skills for Small and Medium Sized Enterprises project. European Commission, Directorate-General for Enterprise and Industry. Retrieved on June 30, 2014 at: http://eskills-guide.eu/news/single-view/article/lead-e-leadership-skills-forsmall-and-medium-sized-enterprises.

Kenny, D.A., \& McCoach, D.B. (2003). Effect of the Number of Variables on Measures of Fit in Structural Equation Modeling. Structural Equation Modeling, 10(3), 333-351.

Korosteleva, J., \& Belitski, M. (2015). Entrepreneurial Dynamics and Higher Education Institutions in the Post-Communist World. Regional Studies, 1-15.

Liu, K., \& Li, W. (2015). Organisational Semiotics for Business Informatics. Routledge, UK. Isenberg, D.J. (2010). How to start an entrepreneurial revolution. Harvard Business Review, 88(6), 41-49.

Levie, J.D., \& Autio, E. (2008). A theoretical grounding and test of the GEM model. Small Business Economics, 31(3), 235-263.

Levie, J.D., \& Autio, E. (2011). Regulatory burden, rule of law, and entry of strategic entrepreneurs: an international panel study. Journal of Management Studies 48, 1392-1419.

Levie, J.D., \& Autio, E. (2014). Hard facts or soft insights? Fact-based and participative approaches to entrepreneurship ecosystems policy analysis and management. Paper prepared for the workshop organised by the Henley Centre for Entrepreneurship, December 2014.

McDonald, R.P., \& Ho, M. (2002). Principles and Practice in Reporting Statistical Equation Analyses. Psychological Methods, 7(1), 64-82.

McMullen, J.S., Bagby, D.R., \& Palich, L.E. (2008). Economic freedom and the motivation to engage in entrepreneurial action. Entrepreneurship Theory and Practice, 32(5), 875-895.

Malecki E.J. (2011). Connecting local entrepreneurial ecosystems to global innovation networks: open innovation, double networks and knowledge integration. International Journal of Entrepreneurship and Innovation Management, 14, 36-59.

Marshall, A. (1920). Principles of Economics. London: Macmillan, 8th edition

Mason, C., \& Brown, R. (2012). Entrepreneurial Ecosystems and Growth Oriented Entrepreneurship. Paper prepared for the workshop organised by the OECD LEED Programme and the Dutch Ministry of Economic Affairs, November 2013. Retrieved June $20^{\text {th }}, 2014$ at: http://www.oecd.org/cfe/leed/Entrepreneurial-ecosystems.pdf

McCann, P., \& Ortega-Argilés, R. (2013). Smart specialization, regional growth and applications to European Union cohesion policy. Research policy, 1-12.

Napier, G., \& Hansen, C. (2011). Ecosystems for Young Scalable Firms. Copenhagen: FORA Group.

Nathan, M. (2012). After Florida: Towards an economics of diversity. European Urban and Regional Studies. doi: 10.1177/096977641246337.

Nelson, R. R. (1993). National Innovation Systems: A Comparative Analysis. New York: Oxford University Press. 
Noorderhaven, N., Thurik, R., Wennekers, S., \& van Stel, A. (2004). The role of dissatisfaction and per capita income in explaining self-employment across 15 European countries. Entrepreneurship Theory and Practice, 28(5), 447-466.

Reynolds, P., Storey, D. J., \& Westhead, P. (1994). Cross-national comparisons of the variation in new firm formation rates. Regional Studies, 28(4), 443-456.

Reynolds, P. D., Bosma, N., Autio, E., Hunt, S., De Bono, N., Servais, I., et al. (2005). Global entrepreneurship monitor: Data collection design and implementation: 1998-2003. Small Business Economics, 24, 205-231.

Rodriguez-Pose, A. (2013) Do Institutions Matter for Regional Development? Regional Studies, 47, 1034-1047.

Saxenian, A.L. (1994) Regional Advantage: Culture and Competition in Silicon Valley and Route 128. Cambridge, MA: Harvard University Press.

Stam, E. (2008). Entrepreneurship and Innovation Policy, In: B. Nooteboom and Stam, E. (eds), Micro-Foundations for Innovation Policy, Amsterdam: Amsterdam University Press: 135-72.

Stam, E., \& Nooteboom, B. (2011). Entrepreneurship, Innovation and Institutions. In: Audretsch, D., Falck, O. \& Heblich, S. (eds) Handbook of Research on Innovation and Entrepreneurship. Cheltenham: Edward Elgar. 421-438.

Stam, E. (2014). The Dutch entrepreneurial ecosystem. Retrieved October 24, 2014 at: http://papers.ssrn.com/sol3/papers.cfm?abstract_id=2473475

Sternberg, R. (2009). Regional dimensions of entrepreneurship. Foundations and Trends in Entrepreneurship 5, Now Publishers.

Stenholm P., Acs, Z.J., \& Wuebker, R. (2013). Exploring Country-level Institutional Arrangements on the Rate and Type of Entrepreneurial Activity. Journal of Business Venturing, 28(1), 176-193.

Stuetzer, M., Obschonka, M., Brixy, U., Sternberg, R., \& Cantner, U. (2014). Regional characteristics, opportunity perception and entrepreneurial activities. Small Business Economics, 42(2), 221-244.

Szerb, L., Acs, Z., Autio, E., Ortega-Argiles, R., Komlosi, E. et. al. (2013). REDI: The Regional Entrepreneurship and Development Index - Measuring regional entrepreneurship. Final Report. European Commission, Directorate-General for Regional and Urban policy. REGIO DG 02 - Communication.

WEF (2013). Entrepreneurial Ecosystems Around the Globe and Company Growth Dynamics. World Economic Forum: Davos.

Woolley, J. L. (2014). The creation and configuration of infrastructure for entrepreneurship in emerging domains of activity. Entrepreneurship Theory and Practice, 38(4), 721-747.

Wright, M., \& Stigliani, I. (2012). Entrepreneurship and Growth. International Small Business Journal, 31(1), 3-22.

Wright, M. (2014). Incubator Biodiversity, Entrepreneurial Ecosystems \& Regional Development. Paper prepared for the workshop organised by the Henley Centre for Entrepreneurship, December 2014.

Yoo, Y., Henfridsson, O., \& Lyytinen, K. (2010). Research commentary-The new organizing logic of digital innovation: An agenda for information systems research. Information Systems Research, 21(4), 724-735.

Zacharakis, A., Shepard, D., \& Coombs, J. (2003). The development of venture-capitabacked internet companies: An ecosystem perspective. Journal of Business Venturing, 18, 217-231.

Zahra, S.A., \& Wright, M. (2011). Entrepreneurship's next act. The Academy of Management Perspectives, 25(4), 67-83. 
Table 1. Cities included in this study

\begin{tabular}{|c|c|c|c|c|c|}
\hline City & Obs. & Country & City & Obs. & Country \\
\hline Aalborg & 2 & Denmark & Palermo & 2 & Italy \\
\hline Graz & 2 & Austria & Roma & 3 & Italy \\
\hline Wien & 3 & Austria & Torino & 3 & Italy \\
\hline Antwerp & 3 & Belgium & Verona & 2 & Italy \\
\hline Brussels & 3 & Belgium & Riga & 2 & Latvia \\
\hline Liege & 3 & Belgium & Vilnius & 2 & Lithuania \\
\hline Burgas & 2 & Bulgaria & Luxembourg & 3 & Luxembourg \\
\hline Sofia & 2 & Bulgaria & Valletta & 2 & Malta \\
\hline Lefkosia & 2 & Cyprus & Amsterdam & 3 & Netherlands \\
\hline Ostrava & 2 & Czech & Groningen & 2 & Netherlands \\
\hline Praha & 2 & Czech & Rotterdam & 3 & Netherlands \\
\hline Copenhagen & 2 & Denmark & Bialystok & 2 & Poland \\
\hline Tallinn & 2 & Estonia & Gdansk & 2 & Poland \\
\hline Helsinki & 3 & Finland & Krakow & 2 & Poland \\
\hline Oulu & 2 & Finland & Warszawa & 2 & Poland \\
\hline Bordeaux & 2 & France & Braga & 3 & Portugal \\
\hline Lille & 2 & France & Lisbon & 3 & Portugal \\
\hline Marseille & 3 & France & Bucharest & 2 & Romania \\
\hline Paris & 3 & France & Cluj-Napoca & 2 & Romania \\
\hline Rennes & 3 & France & Piatra-Neamt & 2 & Romania \\
\hline Strasbourg & 2 & France & Bratislava & 2 & Slovakia \\
\hline Berlin & 3 & Germany & Kosice & 2 & Slovakia \\
\hline Dortmund & 3 & Germany & Ljubljana & 2 & Slovenia \\
\hline Essen & 2 & Germany & Barcelona & 3 & Spain \\
\hline Frankfurt-Oder & 1 & Germany & Madrid & 3 & Spain \\
\hline Hamburg & 2 & Germany & Malaga & 3 & Spain \\
\hline Leipzig & 3 & Germany & Oviedo & 2 & Spain \\
\hline Munchen & 3 & Germany & Malmo & 2 & Sweden \\
\hline Athina & 3 & Greece & Stockholm & 3 & Sweden \\
\hline Irakleio & 3 & Greece & Belfast & 2 & UK \\
\hline Budapest & 2 & Hungary & Cardiff & 2 & UK \\
\hline Miskolc & 2 & Hungary & Glasgow & 3 & UK \\
\hline Dublin & 3 & Ireland & London & 3 & UK \\
\hline Bologna & 2 & Italy & Manchester & 3 & UK \\
\hline Napoli & 3 & Italy & Newcastle & 2 & UK \\
\hline
\end{tabular}

Source: Number of observations 169 as it includes Perception surveys by Eurostat 2004, 2006, 2009; Urban Audit (2004-2010), Eurostat (2014) 
Table 2: Descriptive statistics

\begin{tabular}{|c|c|c|c|c|c|c|}
\hline Conditions & Variables & Variable description & Mean & St. dev & Min & $\operatorname{Max}$ \\
\hline Dep. variable & New firms & Prop. of new firm start-ups in a city, $\%$ & 14.91 & 12.73 & 0.4 & 56.9 \\
\hline \multirow{3}{*}{ Culture and norms $\mathbf{H 1}$} & Safety score 1 & Feel safe in this neighbourhood (0-100) & 89.8 & 7.2 & 59.8 & 99.6 \\
\hline & Safety score 2 & Feel safe in this city $(0-100)$ & 84.2 & 10.8 & 42.3 & 99.2 \\
\hline & Trust & Most people can be trusted (0-100) & 64.9 & 17.8 & 22.3 & 93.5 \\
\hline \multirow{4}{*}{$\begin{array}{l}\text { Infrastructure and } \\
\text { amenities } \mathbf{H 2}\end{array}$} & Transport & Satisfied with transport $(0-100)$ & 71.8 & 17.8 & 2.3 & 96.0 \\
\hline & Green space & Satisfied with green space $(0-100)$ & 72.6 & 17.1 & 23.0 & 95.6 \\
\hline & Clean city & This is a clean city $(0-100)$ & 52.9 & 22.5 & 8.2 & 96.5 \\
\hline & Culture amenity & Satisfied with cultural facilities (0-100) & 86.1 & 11.4 & 45.9 & 99.4 \\
\hline Internet access $\mathbf{H 3}$ & Internet & Satisfied with Internet access (0-100) & 59.5 & 12.2 & 27.8 & 88.7 \\
\hline \multirow{2}{*}{ Formal institutions $\mathbf{H 4}$} & Resources & Resources spent responsibly (0-100) & 49.3 & 16.8 & 11.5 & 82.5 \\
\hline & Administration & Administrative services help efficiently $(0-100)$ & 80.0 & 7.9 & 52.7 & 92.0 \\
\hline The Melting Pot $\mathbf{H 5}$ & Foreigners & Foreigner here are well integrated $(0-100)$ & 57.8 & 16.8 & 10.0 & 91.6 \\
\hline \multirow{2}{*}{ Demand H6 } & Home demand & Demand for housing is high $(0-100)$ & 70.3 & 19.2 & 21.7 & 97.3 \\
\hline & Jobs & It is easy to find a good job $(0-100)$ & 35.6 & 17.8 & 2.6 & 74.8 \\
\hline Control & GDP & GDP per capita in PPP 2000 prices of NUTS3 in logs & 10.2 & 0.5 & 8.5 & 11.2 \\
\hline Control & REDI & Regional Entrepreneurship and Development Index (0-100) & 47.5 & 15.6 & 18.4 & 82.2 \\
\hline
\end{tabular}

Source: Eurostat (2014). Perception surveys 2004, 2006, 2009; Urban Audit (2003-2010) 
Table 3. Rotated factor loading (pattern matrix) and inter-item correlations

\begin{tabular}{|c|c|c|c|c|c|c|c|}
\hline Framework conditions (variables) & Factor 1 & Factor 2 & Factor 3 & Factor 4 & Factor 5 & Factor 6 & uniqueness \\
\hline Transport & -0.10 & $\mathbf{0 . 7 5}$ & 0.39 & -0.15 & -0.07 & -0.07 & 0.25 \\
\hline Green space & 0.29 & $\mathbf{0 . 6 8}$ & -0.06 & 0.20 & 0.01 & 0.07 & 0.16 \\
\hline Clean city & 0.59 & 0.35 & 0.01 & 0.02 & 0.33 & -0.03 & 0.24 \\
\hline Culture amenity & -0.05 & $\mathbf{0 . 7 0}$ & -0.03 & 0.35 & -0.19 & 0.11 & 0.17 \\
\hline Home demand & -0.04 & 0.11 & -0.25 & -0.25 & 0.07 & $\mathbf{0 . 9 7}$ & 0.09 \\
\hline Internet & 0.00 & 0.13 & -0.12 & $\mathbf{0 . 9 7}$ & 0.17 & -0.15 & 0.10 \\
\hline Jobs & 0.10 & -0.19 & 0.38 & 0.31 & 0.00 & $\mathbf{0 . 6 1}$ & 0.17 \\
\hline GDP & -0.01 & 0.17 & 0.15 & 0.08 & $\mathbf{- 0 . 6 1}$ & 0.35 & 0.19 \\
\hline Foreigners & -0.12 & -0.04 & 0.20 & 0.19 & $\mathbf{0 . 9 5}$ & 0.12 & 0.15 \\
\hline Administration & -0.04 & 0.10 & $\mathbf{0 . 9 1}$ & 0.06 & 0.02 & -0.18 & 0.13 \\
\hline Resources & 0.23 & 0.09 & $\mathbf{0 . 7 5}$ & -0.28 & 0.20 & 0.06 & 0.14 \\
\hline Safety score1 & $\mathbf{0 . 9 2}$ & 0.01 & 0.00 & -0.01 & -0.10 & 0.07 & 0.13 \\
\hline Safety score2 & $\mathbf{0 . 9 8}$ & -0.05 & 0.04 & -0.02 & 0.02 & 0.09 & 0.06 \\
\hline Trust & $\mathbf{0 . 8 4}$ & -0.02 & 0.04 & 0.03 & -0.26 & -0.22 & 0.14 \\
\hline Inter-item correlation & & & 0.81 & & 0.18 & 0.65 & \\
\hline Scale reliability coefficient (Chronbach's alpha) & 0.76 & 0.78 & & & & 3.38 & 130.4 \\
\hline Avg. inter-item covariance & 113.1 & 145.65 & 142.3 & & \\
\hline
\end{tabular}

Note: Safety and trust perceptions refer to culture and norms; Administration and resources perceptions refer to formal institutions; job market and demand for housing refer to demand; transport, cultural facilities and green spaces refer to physical conditions (amenities; Internet access refers to Internet; Foreigners and GDP refer to Melting Pot Index. Total observations for all variables: 169 within 60 European cities. Rotation criteria (oblimin) was applied with respect to the orthogonal and/or oblique class of rotations. Cronbach's alpha represents the expected correlation of one test with an alternative form containing the same number of items. The square root of $\alpha$ is the estimated correlation of a test with errorless true scores. Source: Eurostat (2014) 
Table 4: Structural equation model - Entrepreneurial ecosystem: DV -Startup rate

\begin{tabular}{|c|c|c|}
\hline Variable & Full model & Reduced model \\
\hline REDI & $0.29 * * *(0.01)$ & $0.29 * * *(0.00)$ \\
\hline Latent variable: Framework & $4.17 * *(1.95)$ & $8.02 * * *(2.70)$ \\
\hline Factor 1 to framework & 1 & 1 \\
\hline Factor 2 to framework & $0.95 * * *(0.17)$ & $1.60 * * *(0.53)$ \\
\hline Factor 3 to framework & $0.89 * * *(0.16)$ & $0.86 * * *(0.14)$ \\
\hline Factor 4 to framework & $0.44 * *(0.20)$ & $0.46^{* *}(0.15)$ \\
\hline Factor 5 to framework & $-0.17(0.11)$ & -- \\
\hline Factor 6 to framework & $0.05(0.13)$ & -- \\
\hline Variance factor 1 & $0.45(0.10)$ & $0.67(0.12)$ \\
\hline Variance factor 2 & $0.50(0.11)$ & $0.18(0.25)$ \\
\hline Variance factor 3 & $0.56(0.10)$ & $0.75(0.11)$ \\
\hline Variance factor 4 & $0.88(0.08)$ & $0.92(0.10)$ \\
\hline Variance factor 5 & $0.97(0.12)$ & \\
\hline Variance factor 6 & $0.99(0.09)$ & \\
\hline Covariance of errors factor 1 and 3 & - & $0.22 * *(0.10)$ \\
\hline Log likelihood & -5862.44 & -5383.23 \\
\hline chi2 test & 132.04 & 35.4 \\
\hline
\end{tabular}

Note: Number of observations - 950. Estimation method: maximum likelihood with missing values. Standard errors are robust in parenthesis. Reduced model after correction for goodness of fit and other post estimation statistics described in section 3.3 "Analysis".

Source: Eurostat (2014)

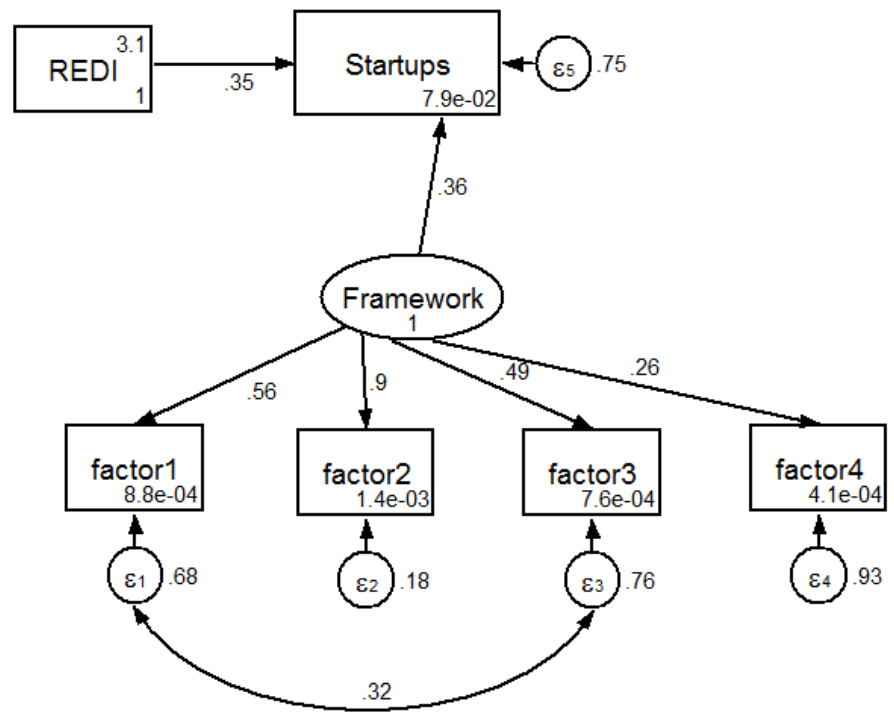

Figure 1: Structural equation model - Entrepreneurial ecosystem framework conditions Note: Estimates are in standardised view. 